\title{
Pan-PI3K/mTOR Inhibitor SF1126
}

National Cancer Institute

\section{Source}

National Cancer Institute. pan-PI3K/mTOR Inhibitor SF1126. NCI Thesaurus. Code C85469.

A water soluble, small-molecule prodrug containing the pan-PI3K/mTOR inhibitor LY294002/SF1101 conjug ated to the RGD-containing tetra-peptide SF1174 with potential antineoplastic and antiangiogenic activities. The targeting peptide SF1174 moiety of panPI3K/mT OR inhibitor SF1126 selectively binds to cell surface integrins and, upon cell entry, the agent is hydrolyzed to the active drug SF1101; SF1101 selectively inhibits all isoforms of phosphoinositide-3-kinase (PI3K) and other members of the PI3K superfamily, such as the mammalian target of rapamycin (mTOR) and DNA-PK. By inhibiting the PI3K signaling pathway, this agent may inhibit tumor cell and tumor endothelial cell proliferation and survival. 